\title{
POLÍTICAS DE FORMAÇÃO CONTINUADA DE PROFESSORES DA EDUCAÇÃO BÁSICA, EM MATO GROSSO, A PARTIR DOS ANOS DE 1990
}

\section{CONTINUED TRAINING POLICIES OF TEACHERS OF BASIC EDUCATION, IN MATO GROSSO, FROM THE YEARS OF 1990}

\author{
Haroldo Borges \\ Mestre em Educação pela UNEMAT. \\ Professor da Educação Básica - SEDUC/MT \\ E-mail: haroldo.professor@gmail.com \\ Heloisa Salles Gentil \\ Doutora pela UFRG \\ Professora na UNEMAT \\ E-mail:logentil2@gmail.com \\ Neures Batista de Paula Soares \\ Mestre em Linguística pela UNEMAT. \\ Doutoranda na UNEMAT (com bolsa de pesquisa pela CAPES) \\ E-mail: Neures_paula@hotmail.com
}

\begin{abstract}
Resumo: Esse tex to tem como objetivo principal compreender como, em Mato Grosso, a escola vem desenvolvendo suas práticas de formação continuada, considerando o percurso histórico de implantação e implementação das políticas de educação e de formação continuada, do Estado, a partir da década de 90 do século XX. Tomamos a concepção de formação presente no documento que trata da política de formação continuada em Mato Grosso, para compreender se/de que modo as escolas da rede estadual de ensino assumem, (re)significam a proposta de formação elaborada pela SEDUC/MT. Nesse sentido, realizamos um percurso de leitura sobre a implantação das principais políticas educacionais e, programas e projetos de formação continuada de Mato Grosso.Como recorte do material, delimitamos o Projeto Sala de Educador, para pensar as possíveis relações com os processos de planejamento do trabalho pedagógico e se o mesmo contribui para a constituição de um coletivo de professores mais autônomos para atuar em contextos de práticas pedagógicas próprios.As leituras e análises ora realizadas, nos levaram a compreender que os profissionais da escola, planejam e desenvolvem a formação continuada, buscando conciliar as temáticas apontadas pela SEDUC/MT e, suas próprias demandas e condições de realizá-las.
\end{abstract}

Palavras-chave: Políticas de Educação; Sala de Educador; Profissionais da Educação.

Abstract:This text has as main objective to understand how, in Mato Grosso, the school has
been developing its practices of continuous formation, considering the historical route of
implantation and implementation of the policies of education and of continuous formation, of
the State, from the decade of 90 of the twentieth century. We take the training conception
present in the document that deals with the policy of continuous training in Mato Grosso, to
understand if / in what way the schools of the state education network assume (re) signify the
training proposal elaborated by SEDUC / MT. In this sense, we conducted a reading course on

${ }^{1}$ Este texto é parte da dissertação de Mestrado em Educação "Práticas de formação continuada de professores da Educação Básica em Mato Grosso: o caso do Projeto Sala de Educador em São Félix do Araguaia.” 
the implementation of the main educational policies and programs and projects for continuing education in Mato Grosso. As a clipping of the material, we delimited the Educator Room Project to think about possible relationships with the pedagogical work planning processes and whether it contributes to the constitution of a more autonomous teachers' collective to act in contexts of their own pedagogical practices. The readings and analyzes carried out led us to understand that the professionals of the school plan and develop continuing education, seeking to reconcile the themes pointed out by SEDUC / MT and their own demands and conditions to carry them out.

Keywords:Education Policies; Educator Room; Education Professionals.

\section{Introdução}

Neste trabalho buscamos compreender as políticas de formação continuada de professores da Educação Básica, em Mato Grosso, tomando o contexto dos anos de 1990, como ponto de partida, para compreender como se constituíram as principais políticas de formação deste Estado. Para esta análise, abordamos legislações, decretos, pareceres pertinentes às políticas, e o diálogo de alguns pesquisadores das políticas de educação e formação de professores em Mato Grosso, como, Rocha (2001); Gentil (2002), Nogueira (2007), dentre outros, e construímos uma contextualização dessas políticas.

Em seguida, colocamo-nos a propósito de explicitar e refletir sobre o Projeto Sala de Educador (PSE), enquanto política de formação continuada institucionalizada pelo Estado de Mato Grosso, desde 2003. Analisamos desde as leis e decretos pertinentes aodesenvolvimento do PSE, como também, algumas pesquisas já realizadas sobre este projeto. De igual modo,procuramos compreender como se deu seu processo desenvolvimento pelas escolas da rede estadual de ensino desde sua implantação, bem como algumas ações e projetos de formação, desencadeadas neste espaço de formação, e o modo como esse conjunto de políticas e projetos tem refletido no locus de formação, ou seja, na escola.

\section{As políticas de formação continuada em Mato Grosso nas três últimas décadas}

A década de 1990 demarcou um espaço-tempo no Brasil para uma série de reformas político-educacionais que deram o tom ao desenvolvimento de várias ações no campo educacional. Boa parte dessas reformas foram conquistas decorrentes dos diferentes movimentos dos educadores da década de 1980, que atuaram na mobilização, realização e participação em congressos e conferências nacionais de educação. 
Nesse contexto, tivemos a aprovação da LDBEN Lei 9.394/1996. Essa lei possibilitou mudanças em outras políticas educacionais, forçando os sistemas públicos de ensino a desenvolverem políticas públicas que atendessem às demandas educacionais, dentre elas as relacionadas à formação inicial e continuada dos profissionais da educação e a profissionalização docente, que deveria ser concretizada com a aprovação de um plano de carreira, cargos e salários dignos.

A LDBEN de 1996 atende, em parte, às referidas demandas dos educadores ao tornar obrigatória a oferta de formação continuada e orientar que os sistemas de ensino garantam uma parte do horário de trabalho dos professores destinada para essa formação.

No artigo $13^{\circ}$ da LDBEN/96 temos a seguinte orientação em relação aos docentes:

V - ministrar os dias letivos e horas-aula estabelecidos, além de participar integralmente dos períodos dedicados ao planejamento, à avaliação e ao desenvolvimento profissional. (BRASIL, 1996).

Nesse sentido, é a partir dessa determinação da Lei 9.394/96 que contextualizamos a política de formação continuada para os profissionais da educação de Mato Grosso, a qual teve sua regulamentação efetivada pela Lei Complementar 49/98que garantiu a valorização dos profissionais da educação, atendendo, assim, ao preconizado nas diretrizes da LDBEN,conforme reza o documento Política de Formação dos Profissionais da Educação Básica de Mato Grosso ${ }^{2}$, publicado pela SEDUC/MT em 2010:

\begin{abstract}
A Lei Complementar fortalece o desenvolvimento de políticas que visam à formação inicial e continuada e articula-se com a Lei Complementar 50/98, que garante a carreira única para os profissionais da educação básica e o piso salarial, além de definir a jornada de trabalho com previsão de hora-atividade, compreendida como o período reservado a estudos, planejamento, preparação de aulas e avaliação, incluída na jornada de trabalho dos professores em função docente. (MATO GROSSO, 2010, p.12).
\end{abstract}

É no contexto de todo esse processo, de estruturação legal das políticas educacionais para a educação, que Mato Grosso vai desenhando e desenvolvendo um conjunto de ações, projetos e programas de formação inicial e continuada para os profissionais da Educação Básica. Concordamos com a ênfase que é dada pelo documento, ora citado, no que tange a importância da política de formação. Diz o texto:

Enquanto política pública de educação, a política de formação em Mato Grosso busca deslocar a formação da responsabilidade individual para a responsabilidade pública; procura inseri-la no contexto das políticas públicas para transformá-la em

\footnotetext{
${ }^{2}$ Este documento apresenta o contexto e a concepção de formação continuada para a rede estadual de MT. O processo de criação dos CEFAPROS (Centros de Formação e Atualização dos Profissionais da Educação Básica, bem como as Diretrizes e Políticas de formação a serem desencadeadas e desenvolvidas através desses centros.
} 
compromisso, com a valorização profissional e destaque do papel da escola no contexto das transformações sociais. (MATO GROSSO, 2010, p. 14).

No referido documento, o Estado apresenta uma concepção de política de formação coerente com as principais discussões teórico-conceituais sobre a formação continuada de professores, trazendo autores como Nóvoa, Imbernón, Pimenta e Alarcão entre outros, que estudam sobre práticas de formação continuada, na perspectiva da superação de ações individuais e fragmentárias, para um comprometimento coletivo no contexto da escola.

Para compreender o contexto da institucionalização dessa política de formação, precisamos trazer à memória os movimentos de lutas da categoria dos profissionais da educação na década de 1990, que culminaram com a aprovação da LC 50/1998, que define em seu Artigo $2^{\circ}$, a responsabilidades do Sistema Público Educacional:

\footnotetext{
Parágrafo único - Os órgãos do Sistema Público Educacional devem proporcionar aos profissionais da Educação Básica valorização mediante formação continuada, piso salarial profissional, garantia de condições de trabalho, produção científica e cumprimento da aplicação dos recursos constitucionais destinados à educação. (MATO GROSSO, 1998, grifo nosso).
}

Estudos e pesquisas desenvolvidas por outros pesquisadores sobre programas e projetos de formação inicial e continuada dos profissionais da Educação Básica em Mato Grosso nos ajudam a compreender a importância das reformas político-educacionais ocorridas nos anos de 1990 no Brasil e seus reflexos no contexto das políticas desenvolvidas no estado, nesse mesmo período.

Segundo Gentil (2002), o Conselho Estadual de Educação de Mato Grosso - CEE/MT, em 1993, defendeu, em documento apresentado para o Plano Decenal de Educação para Todos, a necessidade de uma política de formação e capacitação dos profissionais do magistério para atender à obrigação de Universalização e Qualidade do Ensino. Esse foi o texto sugerido pelo CEE/MT ao Plano Decenal de Educação para Todos: "valorização do Profissional de Educação - formação - plano de carreira - capacitação permanente e garantia das condições de trabalho." (SEE/MT, 1996, p.62, apud GENTIL, 2002, p.92).

A autora (Idem) sinaliza o protagonismo de Mato Grosso em relação às políticas educacionais ao contextualizar a participação do Estado nos debates nacionais sobre os rumos dessa política para a profissionalização e valorização dos profissionais da Educação Básica.

Ainda segundo Gentil (Ibidem), a política educacional do início dos anos de 1990, teve características e identidades muito próprias, uma vez que as demandas por formação surgidas 
dos movimentos sociais de determinadas regiões do Estado são assumidas na perspectiva e na utopia de consolidar, por meio da educação, a emancipação dos sujeitos.

Em relação à microrregião Norte Araguaia, no interior de Mato Grosso, de acordo com Gentil (2002), houve, no início dos anos de 1990, um conjunto de municípios que se preocuparam em desenvolver uma política de formação de seus docentes:

\begin{abstract}
De forma conjunta, esses municípios ${ }^{3}$ privilegiaram a educação elegendo uma política de formação de professores como prioridade e buscando em nível estadual, apoio e respaldo para sua implantação. Bandeira de luta durante as campanhas políticas e dívida social para com a comunidade, a educação passou a ser alvo de árduo trabalho das novas administrações, em busca de soluções para os problemas regionais que não deixavam de ser semelhantes aos nacionais: qualidade da educação e formação dos profissionais para essa área, encarada como caminho para a solução desse problema. (GENTIL, 2002, p.59).
\end{abstract}

Essa contextualização dos movimentos políticos e sociais, de forma conjunta, está voltada para a oferta da educação e para a demanda por formação de professores; diferentes lideranças políticas e educacionais forjaram, na luta, o atendimento dessas necessidades e, por isso, talvez, alguns programas e projetos de formação foram constituídos e desenvolvidos com uma identidade própria - isto é, com cara, cores, sonhos, corpos, culturas, histórias de lutas do povo, que fizeram e participaram de um projeto político educacional na microrregião do Norte Araguaia.

Ainda no exercício de compreender as relações e reflexos das reformas político educacionais com os esforços empreendidos no contexto mato-grossense para dar conta dos desafios da oferta e qualidade educacional a todos, Gentil (2002), afirma que, a partir da década de 1990,

Os professores locais já se sentem parte integrante dos movimentos estaduais; através da ligação com um sindicato próprio da categoria, discutem e reivindicam entre seus pares, a elaboração das políticas educacionais locais, se submetem a disposições vindas de instituições "competentes" da esfera estadual ou federal. Lutam pelo reconhecimento profissional. (GENTIL, 2002, p. 52).

O percurso de contextualização histórica que ora traçamos nos permite melhor compreender o lugar e o papel de Mato Grosso, enquanto ator protagonista, por meio de seus diferentes agentes políticos e lideranças educacionais, gestores e representantes do sindicato da categoria dos profissionais da Educação Básica, na formulação de políticas voltadas para a profissionalização docente.

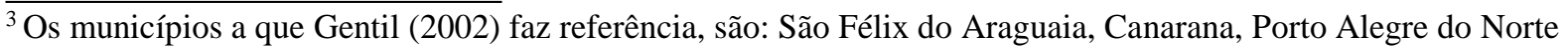
e Santa Terezinha.
} 
É importante ressaltar que esse movimento acontece neste Estado antes mesmo da aprovação da LDBEN nº 9394/1996. Em síntese, as políticas públicas para a educação e formação dos professores, bem como as conquistas relacionadas à valorização e profissionalização dos profissionais da Educação Básica em Mato Grosso, se deram na organização e nas práticas sociais de lutas. A esse exemplo, tem-se o caso do projeto Inajá, o qual foi criado ainda no final dos anos de 1980, em decorrência da demanda social da microrregião Norte Araguaia, apresentada por meio das lideranças políticas representadas pelos prefeitos dos municípios da região, e contou com o apoio da SEDUC/MT para sua realização. Esse projeto teve como objetivo a formação de professores, leigos, que estavam atuando na docência.

Rocha (2001) fala sobre o programa piloto para formação de professores leigos Proformação ${ }^{4}$, desenvolvido em Mato Grosso entre o fim dos anos de 1990 e início dos anos 2000, e o modo como se deu o processo para colocar em prática uma política estadual para a formação de professores leigos. Esse programa de formação foi considerado piloto pelo fato do MEC ter escolhido Mato Groso como o primeiro estado a receber o programa.

Outras políticas de formação de professores foram desenvolvidas em período anterior ao do Proformação. Rocha (2001), ao entrevistar uma das coordenadoras responsáveis pela implantação do Proformação, buscou saber as razões do MEC para a escolha de Mato Grosso para desenvolver o referido projeto. Segundo a coordenadora, Mato Grosso já tinha experiências com formação de professores leigos, a exemplo do projeto GerAção. Foi a partir da avaliação dos limites e dificuldades deste, que se buscou conceber e elaborar o Proformação, procurando garantir a permanência do cursista até o final do curso.

\subsection{A criação dos Centros de Formação e Atualização dos Professores - CEFAPROs}

Na segunda metade da década de 90, a SEDUC/MT já havia identificado vários desafios e limitações para o desenvolvimento da formação diante de realidades tão diversas - extensão territorial, dificuldades de acesso aos polos e aos alunos cursistas, a logística para a organização, distribuição e realização dos acompanhamentos quanto ao trabalho de monitoria, além de outros

2 O PROFORMAÇÃO é um curso de Magistério a Distância, com duração de dois anos letivos, destinado aos professores em exercício no Sistema Público de Ensino, sem habilitação específica de Magistério, com Ensino Fundamental completo4. É um Programa do MEC/SEED/FUNDESCOLA/SEF em parceria com os estados e municípios e que se desenvolve em quatro módulos (semestres de estudos), cada um com 800 horas, cinco Áreas Temáticas, Projetos de Trabalho e prática pedagógica como estágio supervisionado, de 620 horas. A carga horária total do Curso compreende 3200 horas. 
relacionados à logística de produção do material pedagógico e distribuição desses materiais nos prazos previstos. (Cf. ROCHA, 2001)

Ainda de acordo com a autora (2001), em função das condições, ou na falta dessas, o programa Proformação passou por várias adequações para atingir os resultados esperados. Como dito anteriormente, algumas políticas de formação de professores foram implantadas e implementadas em Mato Grosso, no sentido de se constituir a profissionalidade docente, mesmo sendo uma política oficial, emanada do MEC, para atender à demanda por formação de professores frente à obrigação da oferta de educação para todos. Exigências essas já anunciadas na Conferência Mundial de Educação para Todos, no início dos anos de 1990 e, no contexto brasileiro, a regulamentação dessa obrigação só aconteceu com a aprovação da LDBEN no 9394/1996. É nesse contexto que o Estado de Mato Grosso cria o Centro de Formação e Atualização dos Professores (CEFAPRO), ação estratégica para conseguir implementar a urgente política de formação de professores com alcance em todo o território mato-grossense.

Nogueira (2007) faz uma análise das políticas públicas para a formação continuada de professores correspondente ao período de 1995 a 2005. Com a pesquisa, a autora buscou analisar as relações entre as políticas de formação de professores propostas pelos governos para a educação da rede estadual com os dados das avaliações externas realizadas pelo SAEB nesse período, bem como apresentar e contextualizar os programas e projetos desenvolvidos, explicitando todo o processo de criação dos CEFAPROs.

Pelo Decreto $n^{\circ}$ 2007/97, o governo de Mato Grosso criou os CEFAPROs dos municípios de Rondonópolis, Cuiabá e Diamantino. Posteriormente, entre os anos de 1998 e 2008, foram criados outros 12 Centros, instalados nos municípios polos (São Félix do Araguaia, Juína, Barra do Garças, Cáceres, Alta Floresta, Sinop, Confresa, Matupá, Juara, Pontes e Lacerda e Primavera do Leste), totalizando 15 Centros de Formação, distribuídos em regiões estratégicas do Estado de Mato Grosso. Essa organização permitiu atender todos os municípios e todas as escolas estaduais no desenvolvimento de projetos e programas de formação de professores. Conforme o documento que trata da política de formação dos profissionais da Educação Básica de Mato Grosso, “o foco dos CEFAPROs foi o Ensino Fundamental (Escolas Organizadas em ciclos de Formação Humana $-1^{\circ}, 2^{\circ}$ e $3^{\circ}$ ciclos) e, gradativamente, estão estendendo o atendimento para o Ensino Médio e demais modalidades." (MATO GROSSO, 2010, p. 21).

Em um segundo momento, por força da Lei Complementar 50/1998, da ampliação do direito à profissionalização e à formação continuada estendida a todos os profissionais da Educação Básica, os CEFAPROs passaram a atender também a formação dos profissionais não 
docentes. Essa profissionalização foi desenvolvida através do Projeto Arara Azul ${ }^{5}$ que, em 2006, foi substituído pelo Programa Profuncionário ${ }^{6}$.

Os CEFAPROs, tendo como principal função o desenvolvimento da formação inicial e continuada dos profissionais da Educação Básica, passaram a desenvolver programas e projetos formativos já pensados e elaborados por outras instituições. Nas palavras de Nogueira (2007),

[...] para o contexto escolar, os cursos de formação tinham como objetivo garantir a capacitação técnica dos profissionais e a articulação entre as funções específicas de cada um destes segmentos com o projeto global da escola. As formações desenvolvidas davam-se através de projetos como PCNs em Ação, Arara Azul, Salto para o Futuro, Gestar, Proformação ${ }^{7}$. (NOGUEIRA, 2007, p.57).

A partir do trabalho de Nogueira (2007), podemos compreender como se deram as principais ações de formação realizadas pelos CEFAPROs, os quais desenvolveram projetos e programas emanados dos órgãos oficiais de educação, como o MEC e a SEDUC/MT. Em síntese, os centros de formação tiveram pouco espaço para desenvolver ações de formação continuada que pudessem ser decorrentes das demandas das escolas estaduais do polo, uma vez que estavam ocupados com um conjunto de programas e projetos prontos para serem desenvolvidos.

Para compreender, de forma crítica, as experiências de formação continuada em Mato Grosso, tendo a escola como lugar e conteúdo da formação, bem como sua autonomia nos processos de práticas formativas, Rodrigues (2004) traz grande contribuição. Segundo a autora, enquanto a "Escola Vanguarda", foi protagonista do projeto de formação continuada, buscando responder aos desafios da prática docente, desenvolvendo ações de formação docente que atendessem aos anseios e demandas desses, havia maior comprometimento coletivo dos participantes da formação.

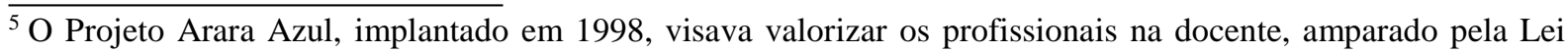
Complementar $n^{\circ} 50 / 98$, que dispõe sobre a carreira dos profissionais da Educação Básica. O Projeto resultou da reivindicação da categoria, representados pelo Sindicato dos Trabalhadores em Educação de Mato Grosso, desde 1986, em reuniões permanentes. (MATO GROSSO, 2010, p.13).

${ }^{6} \mathrm{O}$ Curso Técnico de Formação para os Funcionários da Educação é um curso de educação à distância, em nível médio, voltado para os trabalhadores que exercem funções administrativas nas escolas das redes públicas estaduais e municipais de Educação Básica (MATO GROSSO, 2010, p.28).

${ }^{7}$ PCNs em Ação: capacitação dos gestores e professores de Ensino Fundamental para atuarem com a Escola Ciclada. Projeto Arara Azul: não foi apenas um curso de qualificação profissional para atender a uma determinação legal, mas uma proposta de formação ampla e geral. Além de trabalhar o aspecto acadêmico do conhecimento, desenvolvia uma teia de relações com vistas a elevar a autoestima, abrir horizontes e melhorar a produtividade e o compromisso do funcionário da educação. Quanto ao projeto Gestar,sua finalidade era contribuir para a qualidade do atendimento ao aluno, reforçando a competência e a autonomia dos professores na sua prática pedagógica; O Proformação foi um curso em nível médio na modalidade Normal, Séries Iniciais, por meio da educação a distância. Funcionava em convênio entre o MEC, Estado e Municípios. Os cursistas do Proformação integravam professores leigos em exercício, nas quatro primeiras séries do Ensino Fundamental e classes da alfabetização, das redes públicas das regiões Norte, Nordeste e Centro-Oeste.
} 
Essa experiência contou com a parceria da Universidade Federal de Mato Grosso Campus de Rondonópolis - MT e, posteriormente, com o apoio da SEDUC - MT, quando outras escolas públicas do referido município manifestaram o desejo de participar do projeto de formação desenvolvido pela escola objeto de pesquisa de Rodrigues (2004).

Ainda segundo a pesquisadora, o Estado de Mato Grosso decidiu, a partir dessa experiência, implantar os CEFAPROs e, a partir destes, desenvolver projetos e programas de formação inicial e continuada de professores, enquanto políticas de formação desenhadas pelo MEC e SEDUC-MT, para atender às demandas por formação inicial e continuada do Estado. Ao assumir essa condição, os CEFAPROs deixam de ter "autonomia, flexibilidade e trabalho em conjunto" com as escolas estaduais. (RODRIGUES, 2007, p. 9). Esses centros de formação passaram a executar as políticas educacionais do estado, através da Superintendência de Desenvolvimento e Formação Profissional - SDF que, em 2007, passou a ser denominada Superintendência de Formação dos Profissionais da Educação Básica - SUFP.

Para Rodrigues (2007), os CEFAPROs, como executores das políticas públicas educacionais, têm pouco espaço para atuar como colaboradores junto às escolas no desenvolvimento dos projetos de formação continuada, e vão se formando.

[...] como centros de difusão das políticas públicas do Estado e seus professores se tornaram multiplicadores, fazendo repasses dos projetos governamentais, orientando, dando palestras, explicando as propostas, fazendo oficinas com os cursistas e acompanhando as escolas nos municípios que integram o polo. (RODRIGUES, 2007, p. 10).

Essa condição dos centros de formação acaba por desenvolver ações e projetos de formação continuada um tanto prescritivas, segundo Rodrigues (2007) e, portanto, próximas do que se tem definido como racionalidade técnica. Essa concepção de formação já foi discutida de forma crítica por alguns teóricos da área de formação de professores, como Nóvoa (2001), Pimenta (2012), Ghedin (2012), Imbernón (2009), dentre outros, os quais chamam a atenção para o caráter de curso, treinamento, capacitação e de reciclagem oferecidos por especialistas aos professores. No caso dos CEFAPROs, foram dois os projetos de formação continuada executados -PCNs em Ação e GESTAR - ambos elaborados por consultores do MEC.

Ghedin (2012, p. 151) reflete sobre as práticas de formação docente, orientadas pela concepção da racionalidade técnica, e salienta que: "A racionalidade técnica defende a ideia de que os profissionais solucionem problemas instrumentais mediante a seleção de meios técnicos". Ao se desenvolver práticas de formação de professores nesta perspectiva, acaba-se 
por ignorar, senão ao menos dar menor destaque para os contextos próprios e únicos em que se desenvolve o fazer docente.

Ao fazer isso, as formações realizadas nesse modelo de treinamento/capacitação terão alcances reduzidos nas práticas docentes, uma vez que se limitam à aplicação das técnicas e metodologias de ensino aprendidas nos cursos de formação continuada. "O questionamento a este tipo de profissionalização é que, quando se esgota o repertório teórico e os instrumentos construídos como referenciais, o profissional não sabe como lidar com a situação”. (GHEDIN, 2012, p.151).

Nos primeiros anos de atuação, os CEFAPROs realizaram ações de formação continuada na forma de cursos. Embora boa parte desses cursos tivessem partido de demandas formativas das escolas que compunham o polo de atuação dos centros de formação, não se tinha, nesse período, o Projeto Sala de Professor/Educador, instituído e implementado como uma política de formação continuada, voltada para atender às demandas formativas dos professores em seus contextos e modalidades de atuação próprios - a escola como locus da formação.

A oferta desses cursos dava-se a partir de temas comuns para todos os profissionais da educação, ignorando os espaços, áreas e modalidades (ciclo de alfabetização, áreas do conhecimento, Educação de jovens e Adultos - EJA e Educação do Campo) específicas de atuação dos docentes. Situação essa que parece refletir em pouco impacto nas mudanças das práticas pedagógicas. E quando tinha algum reflexo nas ações pedagógicas, essas duravam o tempo das atividades aprendidas nos cursos ofertados na modalidade de oficinas para o desenvolvimento de novas técnicas metodológicas de ensino-aprendizagem, como na perspectiva refletida por Ghedin (2012).

Acreditamos que as práticas de formação continuada poderão lograr algum êxito quando compreendermos que:

\begin{abstract}
A formação baseada em situações problemáticas centradas nos problemas práticos responde às necessidades definidas pela escola. A instituição educativa se transforma em lugar de formação prioritário mediante projetos ou pesquisas-ações frente a outras modalidades formativas de treinamento. A escola passa a ser o foco do processo 'açãoreflexão-ação’ como unidade básica de melhoria. (IMBERNÓN, 2009, p. 54).
\end{abstract}

As reflexões de Imbernón (2009) apresentam como alternativas às práticas de formação continuada, fundadas na racionalidade técnica, o desenvolvimento de projetos formativos que considerem o contexto de situações problemas vivenciados pelos docentes em suas práticas pedagógicas. Pensar a escola como lugar da formação é possibilitar a participação dos docentes durante todo o processo de criação e desenvolvimento de planos e estratégias metodológicas 
coerentes com o contexto de suas ações. Na possibilidade de vivenciar esse movimento na formação continuada, podemos tomá-lo como formativo, em que, conteúdo e formas de ensinar devem ser pensados de maneira integrada e complementar às ações de enfrentamento, que o autor denomina de "situações problemáticas".

Com essa perspectiva teórica, em 2010, a SEDUC/MT publicou um documento explicitando a Política de Formação dos Profissionais da Educação Básica. Nesse documento, são definidas algumas funções para os CEFAPROs assessorarem as escolas da rede pública, dentre elas:

\begin{abstract}
Diagnosticar necessidades, apoiar e propor ações formativas junto às escolas da rede pública de ensino; elaborar, acompanhar e avaliar o projeto de formação continuada nas escolas, contribuindo para o desenvolvimento dos profissionais que nela atuam; estimular, divulgar e realizar ações inovadoras, através da troca de experiências, da reflexão e pesquisa sobre a própria realidade educativa; diagnosticar as necessidades e propor projetos de áreas específicas, visando a qualidade do ensino e da aprendizagem; responder às necessidades de melhorar os projetos formativos nas escolas e co-responsabilizar todos os envolvidos nesse processo; disseminar as políticas públicas nacionais e estaduais de formação inicial e continuada em todo território mato-grossense; mediar as necessidades formativas e as políticas oficiais, fortalecendo e dinamizando a rede de formação. (MATO GROSSO, 2010, p. 22).
\end{abstract}

As funções anteriormente explicitadas indicam a concepção e prática de formação continuada a serem implementadas na rede pública de ensino. Essa política de formação proposta se aproxima da compreensão apresentada por Imbernón (2009).

De acordo com essas funções, espera-se o desenvolvimento de práticas de formação continuada coerentes com as demandas das necessidades formativas identificadas nos contextos das práticas pedagógicas. Ação essa que deve se dar no exercício da reflexão crítica sobre a prática docente, mediada com o apoio dos Centros de Formação e acompanhamento dos professores formadores ${ }^{8}$. A seguir, apresentamos o projeto de formação continuada proposto pela SEDUC por meio do Projeto Sala de Educador - PSE.

\title{
2.2 Políticas de Formação Continuada: Projeto Sala de Educador
}

As práticas de formação continuada, desenvolvidas pelas escolas da rede estadual de ensino de Mato Grosso, tiveram sua institucionalização enquanto política pública desde o ano

\footnotetext{
${ }^{8} \mathrm{O}$ professor-formador do CEFAPRO deve ser um pesquisador e um produtor de conhecimentos sobre a educação, sobre o que e como se ensina, investigando na e sobre a prática. Deve estar preparado para permitir que o CEFAPRO seja realmente um espaço de formação e atue como referência de apoio teórico-metodológico ao profissional que está na escola. (MATO GROSSO, 2010, p. 22).
} 
de 2003, com o Programa de formação continuada Sala de Professor, elaborado pela Seduc/MT. De acordo com o documento "Política de formação dos Profissionais da Educação Básica de Mato Grosso" (MATO GROSSO, 2010), o referido programa tinha por princípio a formação continuada dos professores. Coube à Superintendência de Formação dos Profissionais da Educação Básica (SUFP), juntamente com os CEFAPROs, o trabalho de implantar e implementar nas escolas estaduais, esse programa.

O documento orientativo de 2003 define, em seus objetivos, justificativa, metodologia e fundamentos teóricos, que tipo de formação deveria ser desenvolvida pelas escolas, e qual o papel da Seduc/SDF e dos CEFAPROs no apoio às escolas para o desenvolvimento do Projeto Sala de Professor.

A institucionalização do projeto Sala de Professor se deu em meio a um contexto em que os professores já participavam de cursos de formação continuada coordenados pelos Centos de Formação. Eram projetos/programas de formação elaborados pelo MEC, como os já referidos na seção anterior (PCNs em Ação e Proformação), e as formações apresentada pela Seduc para atender às demandas das políticas educacionais do Estado de Mato de Grosso.

Nesse mesmo período, os CEFAPROs desenvolviam ações de formação voltadas para a implantação e implementação da Escola Ciclada de Mato Grosso. Esses cursos foram desenvolvidos segundo o modelo de capacitação. Talvez por isso, o projeto Sala de Professor tenha sido denominado como programa, e não como projeto, no início de sua implantação.

A proposição desse projeto de formação continuada por parte da SEDUC/MT se deu em função da necessidade observada por parte dos gestores de formação dessa secretaria, dos próprios centros de formação, e das escolas que careciam de um projeto de formação continuada próprios. Isso é, que os programas e projetos formativos até então desenvolvidos necessitavam estar articulados a um projeto comum que considerassem as necessidades formativas das escolas. Com essa compreensão, os CEFAPROs tomariam o Projeto Sala de Educador como instrumento estratégico para desenvolver as ações formativas junto às escolas do polo, incentivando, orientando e assessorando as escolas na elaboração e desenvolvimento do projeto de formação.

O próprio Documento Orientativo de 2003 para a elaboração do Projeto Sala de Professor, quanto aos objetivos e propostas de ação, assim descreve:

[...] constitui-se um trabalho voltado para a formação continuada, que tem como objetivo organizar no interior da escola Grupos de Estudos com professores comprometidos com a qualidade do ensino prestado à sociedade. Esta proposta de trabalho surgiu de um desejo originado do meio da classe docente que veio subsidiar a proposta de integrar e articular os Programas e Projetos existentes 
de Formação Continuada, buscando a interface e a interlocução deles com a Política de Formação do Estado. [...] Sala de Professor é denominação dada ao Programa de Formação a Distância e Continuada para o período 2003 a 2006, [...] porta aberta para as novas tendências de linha de pensamento da Educação, isto porque os professores estarão mobilizados para refletir sobre sua ação pedagógica, tornandose protagonistas e co-partícipes do processo de mudança educativa, terão na escola um espaço democrático, que lhes possibilitará efetivar, assim, Política de Governo que delega à Educação a materialização da democracia no ambiente escolar. Pensar na escola como lócus de formação é proporcionar ao professor um espaço e tempo para que este profissional possa investir na sua formação de maneira contínua, individual e coletiva, através da organização dos grupos de estudos. Estes grupos possibilitarão aos professores vivenciarem momentos de estudos, reflexão e abertura para trocas de experiências e debates, tematizando sua prática e buscando soluções, isso deve acontecer de forma articulada a uma metodologia investigativa voltada para a pesquisa da ciência e da realidade sociocultural e econômica do grupo social na qual a escola está inserida. Neste contexto, a SEDUC, através da Superintendência de Desenvolvimento e Formação dos Profissionais da Educação - SDF/MT, atende as expectativas da Comunidade Escolar garantindo, não só aos professores a oportunidade de inserir-se em um grupo de estudo permanente em seu ambiente de trabalho, mas também aos que vêm participando dele a certeza da superação de descontinuidade das ações que têm marcado comumente as trocas de governo e, ao mesmo tempo, oportunidade de planejar e/ou repensar a proposta de formação continuada a partir das necessidades levantadas pelo coletivo da escola. Isso significa que este projeto atenderá, não somente os anseios da escola, como também da sociedade que reivindica uma Educação responsável, democrática e de qualidade, qualidade que passa inevitavelmente pela formação inicial e continuada de seus professores. (MATO GROSSO, 2003, p. 8, grifos nossos).

O documento ora referido traz pontos importantes quanto aos objetivos e propostas para a formação continuada a ser desenvolvida através do Projeto Sala de Professor, pois balizará os documentos orientativos dos anos seguintes até o ano de 2015. Esses documentos orientativos conservaram boa parte dos objetivos desse projeto inicial, como: organização de grupos de estudos; comprometimento coletivo da escola; fortalecimento da escola como locus de formação continuada; trocas de experiências; tematização da prática.

Em 2010, o nome Projeto Sala de Professor foi modificado e passa a ser Sala de Educador, tendo por objetivo atender também os profissionais não docentes - funcionários da escola, que já vinham reivindicando o direito à formação continuada. Com o objetivo de atender à demanda desses profissionais, a SEDUC/MT publicou o documento "Política de Formação para os Profissionais da Educação Básica”. Esse documento atribui aos funcionários da escola o papel de educadores (MATO GROSSO, 2010), o que é coerente com a perspectiva sindical.

Sem pretender apresentar de forma mais detalhada o que cada documento orientativo destaca quanto à forma, metodologia de organização e desenvolvimento da formação, os documentos orientativos trazem sugestões de roteiros para a elaboração do projeto, bem como, os responsáveis pela coordenação, acompanhamento e orientação para o desenvolvimento do mesmo. As responsabilidades e corresponsabilidades são distribuídas desde o órgão central SEDUC/SUFP, CEFAPROs, Assessorias Pedagógicas e Escolas. 
Os documentos "Política de Formação dos Profissionais da Educação Básica de Mato Grosso", publicado em 2010, e o "Projeto Sala de Educador", publicado em janeiro de 2011, demarcam e assumem uma concepção de política e de prática de formação continuada a ser assumida pelo estado de Mato Grosso junto às escolas públicas de Educação Básica. Esses documentos, a começar pelo primeiro, esboçam desde o panorama nacional sobre a formação, passando pelo histórico das políticas e práticas de formação desenvolvidas no contexto de Mato Grosso e descrevem até os diferentes programas e projetos de formação inicial e continuada para professores e profissionais da educação, desenvolvidos neste Estado. $\mathrm{O}$ documento Orientativo de 2010 apresenta as diretrizes e estratégias da política de formação a serem assumidas e executadas como política pública para a formação inicial e continuada dos profissionais da Educação Básica. Uma das diretrizes do documento,

[...] considera que docentes e funcionários de escola formam o coletivo dos profissionais no ambiente escolar, com direito a acesso permanente a oportunidades de formação, de condições dignas de trabalho, carreira e salário, como estratégia de construção e fortalecimento da sua identidade profissional e social. (MATO GROSSO, 2010, p. 37).

Essa diretriz reafirma o que já estava posto como direito dos profissionais não docentes pela $\mathrm{LC} \mathrm{n}^{\circ} 50 / 1998$, que enquadrou todos os funcionários de escola como educadores, desde que se profissionalizassem através do curso Arara Azul, depois substituído pelo Profuncionário.

O segundo documento "Projeto Sala de Educador" - PSE, publicado pela SEDUC em janeiro de 2011, trata de como deve se dar a formação continuada dos profissionais da Educação Básica dos estabelecimentos públicos de ensino. Esse documento, mais do que um orientativo para a elaboração do PSE, como os demais encaminhados às escolas em anos anteriores, tem a preocupação de apresentar de forma mais explícita, os objetivos, a fundamentação teórica, a metodologia, as atribuições dos envolvidos e toma como referencial o documento de 2010, a que nos referimos anteriormente, e os estudiosos que sustentam a concepção da formação continuada centrada na escola, na perspectiva de ampliar a compreensão do professor como prático reflexivo, para o desenvolvimento de uma escola reflexiva, conceito cunhado por Alarcão (2001).

Desejamos uma escola reflexiva, concebida como uma organização que continuamente se pensa a si própria, na sua missão social e na sua organização, e confronta-se com o desenrolar da sua atividade em um processo heurístico simultaneamente avaliativo e formativo. Nessa escola, acredita-se que formar é organizar contextos de aprendizagem, exigentes e estimulantes, isto é, ambientes formativos que favoreçam o cultivo de atividades saudáveis e o desabrochar das capacidades de cada um com vistas ao desenvolvimento das competências que lhes 
permitam viver em sociedade, ou seja, nela conviver e intervir em interação com os outros cidadãos. (ALARCÃO, 2001, p. 11).

Essa necessidade de deslocar a centralidade da formação continuada voltada para o professor, e depositando neste profissional uma carga de responsabilidade pela melhoria dos processos de ensino e aprendizagem, se deu em função da incorporação de todos os profissionais da educação nas práticas de formação continuada. Esse desafio, assumido enquanto política de formação, acarretou a mudança de concepção e prática de formação continuada que deve ser assumida enquanto escola no seu coletivo de profissionais educadores.

Nesse sentido, o espaço de ação da formação continuada extrapola o lugar da sala de aula e passa a ser assumido por todos os sujeitos que atuam no ambiente escolar como espaço educativo-formativo. Essa nova compreensão da formação ainda em construção possibilita o desenvolvimento de um dos objetivos do PSE, que é o fortalecimento do trabalho coletivo da escola.

De acordo com o texto do Projeto Sala de Educador:

\begin{abstract}
Nessa racionalidade de que uma escola reflexiva é uma organização aprendente que qualifica não apenas os que nela atuam, mas também os que nela ensinam ou apoiam estes e aqueles, é que se compreende que para atender ao contexto atual de escola contemporânea, o envolvimento de professores, alunos e funcionários na dinâmica da escola é preponderante. (MATO GROSSO, 2011, p. 14).
\end{abstract}

O que se percebe, a partir da justificativa e da fundamentação teórica, presentes no PSE de 2011, é um esforço de compreensão e orientação para que a formação continuada seja desenvolvida na direção de um comprometimento coletivo, inclusive do órgão central SEDUC, através da SUFP e dos CEFAPROs - responsáveis por orientar, assessorar e acompanhar as escolas no desenvolvimento da formação continuada.

No contexto da implementação do PSE, o estado de Mato Grosso, através da SEDUC, iniciou-se um processo de discussão, debates, seminários escolares, municipais, regionais e estaduais para a construção e implantação das OCs - Orientações Curriculares para a Educação Básica de Mato Grosso ${ }^{9}$. Essas ações mobilizaram a comunidade escolar para o desafio de implementar as OCs, tarefa assumida pela SEDUC, através das Superintendências de Educação Básica (SUEB) e SUFP, essa última, orientou os CEFAPROs para o trabalho com as escolas,

\footnotetext{
${ }^{9}$ As Orientações Curriculares para a Educação Básica do Estado de Mato Grosso surgem fundamentadas na decisão política de fazer chegar ao chão da escola um texto claro e conciso que, a par dessa clareza e concisão, ofereça ao professor uma visão inequívoca do homem e da sociedade que se quer formar. Um retrospecto histórico da educação brasileira, desde a colonização aos dias atuais, permite a visualização de um país aparentemente dual, tanto nas políticas econômicas, quanto sociais.
} 
realizando encontros formativos, orientações para o estudo e avaliação do documento preliminar das OCs.

Parte significativa dessas ações se deu no espaço de formação do PSE, com a participação de todos os profissionais da educação. Esse movimento contribuiu para a compreensão da concepção de formação continuada como uma ação de fortalecimento do trabalho coletivo na construção de um projeto político pedagógico para a escola organizada em ciclos de formação humana.

Em 2012, com o desafio de implementar as Orientações Curriculares no contexto da escola organizada por ciclos de formação humana e na perspectiva da busca pela qualidade social da educação, a SEDUC, através da SUEB, SUFP e CEFAPROs, desenvolveu um trabalho de formação junto às escolas.

A formação foi sobre uma das estratégias metodológicas sugeridas no documento das Orientações Curriculares para a organização e planejamento do ensino - neste caso, a estratégia metodológica escolhida para estudo e implementação, junto às escolas, foi "A investigação sócio antropológica e a organização do ensino por Complexo Temático ${ }^{10 "}$.

No primeiro momento, os gestores e formadores dos Centros receberam uma formação teórico-metodológica, sobre o tema, com carga horária de 24 horas. Em seguida, os formadores organizaram a formação com os professores e coordenadores dos polos, nos mesmos moldes da formação recebida em Cuiabá/MT. Na primeira etapa foi abordada a concepção de investigação sócio antropológica e a organização do ensino por Complexo Temático.

Para discutir esse tema foi convidado o consultor Silvio Rocha, que discutiu o tema a partir da experiência desenvolvida em Porto Alegre/RS, com as escolas municipais através do Projeto Escola Cidadã. Na segunda etapa, houve a formação em formato de oficinas - momento em que se exercitou a experiência da investigação sócio antropológica e se construiu um complexo temático, tomando por referência o documentário "Nas Terras do Bem virá11", os

\footnotetext{
${ }^{10}$ Trata-se de experiência concreta realizada por escolas da Rede Pública Municipal de Porto Alegre/RS. A investigação sócio antropológica é uma entrevista que os professores fazem na comunidade do entorno da escola. Nesta visita, os professores organizam um roteiro de conversas com as famílias procurando registrar as falas que expressam questões concretas que envolvem a comunidade. A sua história, suas lutas, seus ritos e mitos, o circuito de lazer, o tipo de convivência, seu imaginário, enfim seus problemas mais significativos. Em seguida o material apontado é discutido e sistematizado no chamado complexo temático. Este é constituído por um núcleo formado pelo fenômeno mais frequente nas falas da comunidade. Em torno do fenômeno principal são colocadas as falas mais significativas e em torno das falas, os conceitos a elas relacionados. Construído o complexo, as diferentes áreas do conhecimento organizam o programa de ensino a partir do fenômeno e das falas, trabalhando os respectivos conteúdos relacionados com os conceitos e com o fenômeno do complexo. Esta prática estimula o trabalho coletivo, a interdisciplinaridade e possibilita que as questões concretas da comunidade apareçam na linguagem e no conteúdo escolar conferindo significados aos processos de aprendizagem.

${ }^{11} \mathrm{O}$ filme aborda trabalho escravo e conflitos de terra no Pará, e se preocupa em demonstrar que a situação atual do Pará remonta à ditadura militar, tempo de uma campanha pelo desenvolvimento da Amazônia - "terra sem
} 
cadernos das Orientações Curriculares para a Educação Básica e livros didáticos de diferentes disciplinas, a fim de organizar um plano de ensino por área do conhecimento. Esse mesmo exercício foi realizado com todas as escolas do polo de cada CEFAPRO, sob a coordenação da equipe desse órgão. E os professores representantes das escolas estaduais do polo do qual participaram na formação repetiram esta formação na escola.

Assim, compreendemos que todo o processo de implementação das políticas de educação e formação, propostos pela SEDUC/MT, passou pelos CEFAPROs e ocupou o espaço do PSE, para conseguir ser implantado e implementado, sendo, sobretudo, esse último, o lugar de maior incisão inscrição dos profissionais da educação enquanto protagonistas de seus próprios processos de formação.

\section{Considerações}

A nosso ver, o paradoxo das políticas educacionais implantadas pela SEDUC, dentre elas a política de formação continuada dos profissionais da educação, é que, ao mesmo tempo em que o PSE tem por objetivo fortalecer a escola como espaço formativo coletivo e que, a partir de suas demandas próprias, elabora o projeto de formação, deve também atender e assumir as políticas educacionais e de formação advindas do órgão central SEDUC/MT.

Compreendemos que os professores são os verdadeiros sujeitos e protagonistas da formação. O conteúdo da formação são as práticas pedagógicas, estas devem ser problematizadas e refletidas pelo coletivo de profissionais da escola no contexto de atuação destes. Esse movimento deve ser desencadeado na prática da formação, no desenvolvimento do profissional docente, na perspectiva de pensar a sua prática "e construir suas próprias teorias, à medida que refletem, coletivamente, sobre seu ensino e o fazer pedagógico, considerando as condições sociais que influenciam direta ou indiretamente em suas práticas sociais". (MATO GROSSO, 2010, p. 15).

Inferimos da análise das práticas de formação continuada desenvolvidas pela escola, que o coletivo de professores, está constituindo a sua autonomia no desenvolvimento do Projeto Sala de Educador no ponto em que se apropriam da política de formação, (re)significando-a,

homens para homens sem-terra" - que promoveu a migração e a concentração fundiária a despeito de uma defesa do meio-ambiente e das populações mais pobres. E sugere o quanto os peões de hoje tendem a cair ciclicamente na rede da escravidão, enquanto uma mudança estrutural na divisão das terras e no modelo excludente de agronegócio não acontece. Disponível em: <http://reporterbrasil.org.br/2007/03/documentario-aborda-trabalhoescravo-e-conflitos-de-terra-no-para/>. Acesso em 13/06/2016. 
em seus contextos de atuação, visando alterar os processos de planejamento coletivo do trabalho pedagógico.

A prática de pensar o planejamento do trabalho docente integrado às ações de formação continuada evidencia um esforço do coletivo de professores, enquanto escola, em articular teoria e prática no/para o contexto de suas práticas, enquanto escola que reflete, inserida nesse contexto, com suas limitações e possibilidades (materiais e humanas), com as quais tem de lidar cotidianamente no desafio de fazer uma educação democrática, inclusiva e de qualidade social para todos.

Consideramos não ser possível ainda analisar os impactos dessa mudança nas práticas de formação continuada das escolas. O que temos, concretamente, são as práticas de formação continuada desenvolvidas por meio do PSE, que às vezes encontram resistências dos profissionais da educação em função das proposições advindas do órgão central SEDUC/MT, que nem sempre coincidem ou atendem às demandas reais da escola. É nesse espaço de tensão que os profissionais da escola, planejam e desenvolvem a formação continuada, buscando conciliar as temáticas apontadas pela SEDUC/MT e, suas próprias demandas e condições de realizá-las.

Referências

ALARCÃO, Isabel. Professores reflexivos em uma escola reflexiva. 7. ed. São Paulo: Cortez, 2010 (Coleção questões da nossa época; V. 8).

BRASIL. Lei $\mathbf{n}^{\mathbf{9}}$ 9.424, de 24 de Dezembro de 1996. Disponível em: <http://planalto.gov.br/ccivil_03/leis/L9424compilado.htm>. Acesso em 21/08/2016.

CAPES - Coordenação de Aperfeiçoamento de Pessoal de Nível Superior. Banco de teses e dissertações. Disponível em: 〈http://capesdw.capes.gov.br/capesdw/Teses〉. Acesso em: 20/07/2015.

GENTIL, Heloísa Salles. Formação Docente: no balanço da rede entre políticas públicas e movimentos sociais. 136 f.: Dissertação (Mestrado em Educação), Programa de Pós-Graduação em Educação, Porto Alegre: UFRGS, 2002.

GHEDIN, Evandro. Professor Reflexivo: da alienação da técnica à autonomia da crítica. In: PIMENTA, Selma Garrido e GHEDIN, Evandro (Orgs.). Professor reflexivo no Brasil: gênese e crítica de um conceito. 7 ed. São Paulo: Cortez, 2012.

IMBERNÓN, Francisco. Formação Permanente do Professorado: novas tendências. São Paulo: Cortez, 2009. 
NOGUEIRA, Genialda Soares. Política de Formação Continuada de Professores no Estado de Mato Grosso - 1995 - 2005. 147 f.: Dissertação (Mestrado em Educação), Instituto de Educação, Universidade Federal de Mato Grosso, Cuiabá, 2007.

NÓVOA, Antonio. Professor se forma na escola. São Paulo: Abril, Nova Escola (142): 13-15, maio, 2001.

Lei Complementar n. 50, de 01 de outubro de 1998. Dispõe sobre a carreira dos profissionais da educação básica de Mato Grosso. D.O. 1.10.98. Mato Grosso MT, 01 out. 1998. Disponível em: <http://al.mt.gov.br/TNX/viewOrdinaria.php?pagina=8405>. Acesso em: 28 de julho de 2015.

MATO GROSSO (Estado). Projeto Sala de Educador. SEDUC/SUFP (Secretaria de Estado de Educação/Superintendência de Formação dos Profissionais da Educação Básica) - Cuiabá, 2011.

PIMENTA, Selma Garrido. Professor Reflexivo: construindo uma crítica. In: PIMENTA, Selma Garrido e GHDIN, Evandro (Orgs.). Professor reflexivo no Brasil: gênese e crítica de um conceito. 7 ed. São Paulo: Cortez, 2002.

ROCHA, Simone Albuquerque da. Os professores leigos e o Proformação: uma alternativa possível a partir do projeto piloto de Mato Grosso. 312 f.: Tese (Doutorado em Educação), UNESP, Marília, SP, 2001.

RODRIGUES, Silvia de Fátima Pilegi. Práticas de Formação Contínua em Mato Grosso Da Autonomia Professoral à Prescrição da Política Estatal. 300 f. : Tese (Doutorado em Educação), Pontifícia Universidade Católica de São Paulo, SP, Biblioteca Depositária: PUCSP, 2004.

Autonomia e prescrição - formação contínua de professores em Mato Grosso. In: InterMeio: revista do Programa de Pós-Graduação em Educação, Campo Grande, MS, v.13, n.26, p.11-23, jul./dez. 2007.

Política de Formação dos Profissionais da Educação Básica. MATO

GROSSO/SEDUC (Secretaria de Estado de Educação) - Cuiabá, 2010. 